\title{
Post-ACL Reconstruction Graft Failure in Severe Gout Arthritis Patient
}

\author{
Andri Maruli Tua Lubis (iD \\ Adisa Yusuf Reksoprodjo \\ Mohamad Walid Kuncoro \\ Nadia Nastassia Ifran (DD \\ Department of Orthopedic \& \\ Traumatology Cipto Mangunkusumo \\ Hospital, Faculty of Medicine Universitas \\ Indonesia, Jakarta, Indonesia
}

\begin{abstract}
Introduction: Pain and instability following an anterior cruciate ligament (ACL) reconstruction remain a significant issue. Common causes include infection and inflammation, and mechanical issues such as graft failure.
\end{abstract}

Case Presentation: A 36-year-old male with an ACL reconstruction six years prior was admitted due to pain and swelling. The ACL graft that had ruptured was found arthroscopically. Numerous gout crystals and tophus were observed inside. This finding is suggested as a cause of this kind of complication.

Discussion: Biological failure is one of the causes of graft failure. Gout arthritis is associated with internal derangement of the joint structures, which is reported in advanced case.

Conclusion: Severe gouty arthritis, even though rare, could be an etiology of graft failure following ACL reconstruction and cause significant morbidity.

Keywords: ACL reconstruction, graft failure, gout, tophus

\section{Introduction}

Anterior Cruciate Ligament (ACL) rupture is one of the most common ligamentous injuries on the knee among athletic or non-athletic patients. The incidence is about 68.6 cases per 100,000 people per year. ${ }^{1}$ The ACL has become the focus of many anatomical or biomechanical studies, and it is also the most commonly studied structure in the human musculoskeletal system in recent years, due to the frequency of injury and the devastating consequences. ${ }^{2}$

Restoration of stability and return to activity and sports with minimal compromise are the parameters of successful ACL reconstruction. When both of these have not been achieved, graft failure should be considered. ${ }^{3}$ Although the long-term outcome of patients after ACL reconstruction is excellent in $75 \%$ to $90 \%$ of patients, there is $0.7-20 \%$ of patients that have graft failure and recurrent instability. The Common causes of ACL graft failure vary greatly, with technical errors and traumatic injury after reconstruction being the most frequent. ${ }^{4}$

Biological failure is a rare cause of ACL graft failure. This term established when there was no history of subsequent new trauma as well as no detectable technical errors. This can also be defined as a failure in ligamentization that leads to a disorganized tissue graft. ${ }^{3}$ Ligamentization is a process that happens once a graft is implanted, whether it was autograft or allograft underwent biological processes such as graft necrosis, revascularization, cellular repopulation, deposition of collagen fibers, and remodeling. ${ }^{5}$ Gout arthritis is a systemic disease
Department of Orthopaedic \&

Traumatology Cipto Mangunkusumo

National Central Hospital - Faculty of

Medicine Universitas Indonesia, Jl.

Diponegoro No. 7I, Jakarta, Indonesia

Tel +62 816-1 I77-078

Fax +62 2I 3905894

Email andrilubisresearch@gmail.com 
resulting in urate crystal (monosodium urate) deposition on the joint. ${ }^{6}$ In chronic cases, gout arthritis represents a poly-arthropathy accompanied by soft tissue tophaceous deposition. ${ }^{7}$ Cartilage degeneration results in lower urate solubility and promotes urate crystal formation on the articular surface, which can be a reason why it causes internal derangement of the knee joint. ${ }^{89}$ Hussin et al. $(2014)^{10}$ reported a case of total ACL tear associated with intraarticular tophi formation that was found arthroscopically. Hwang et al. (2012) state that tophi deposition promotes degenerative destruction of surrounding tissue and induces fibrinoid necrosis of the tissue result in spontaneous rupture..$^{7,10}$

\section{Case Presentation}

A 36-year-old male, with a previous history of ACL reconstruction six years prior, was admitted due to painful swelling of the knee associated with recurring knee instability. A hamstring graft was used for subsequent ACL reconstruction, and it was performed outside our institution by a senior and experienced surgeon. Patients could walk normally in about 6 months, although heavy sports activity has not yet been achieved. The patient remained without symptoms for the next six years. He began to experience pain and swelling over his knee after a six-year period. There was no history of trauma. There was also stiffness of the knee. The patient had difficulty moving his knee. The patient had a previous history of hyperuricemia without symptoms and did not take medication routinely.

The physical examination revealed a painful, swollen knee without sinus discharge and limitations in knee flexion-extension that ranged from 30 to 80 degrees (Figure 1). Special tests such as the Lachman test as well as the pivot shift test could not be done properly due to the limitation of the knee range of motion. In addition, the left contralateral knee shows similar manifestation clinically with tenderness, mild swelling, stiffness and limited range of motion.

The radiographic finding shows early arthritic changes in the knee. This kind of plain $\mathrm{x}$-ray of the knee resembles a picture of the degenerative condition of joints (Figure 2). Besides, the MRI shows effusion, and there is a suggested solid mass on the posterior part of the femoral notch with suspected arthrofibrosis. The previous graft is nowhere to be seen in Figure 3. Laboratory results prior to the surgery revealed an increase in urate acid level in the serum of

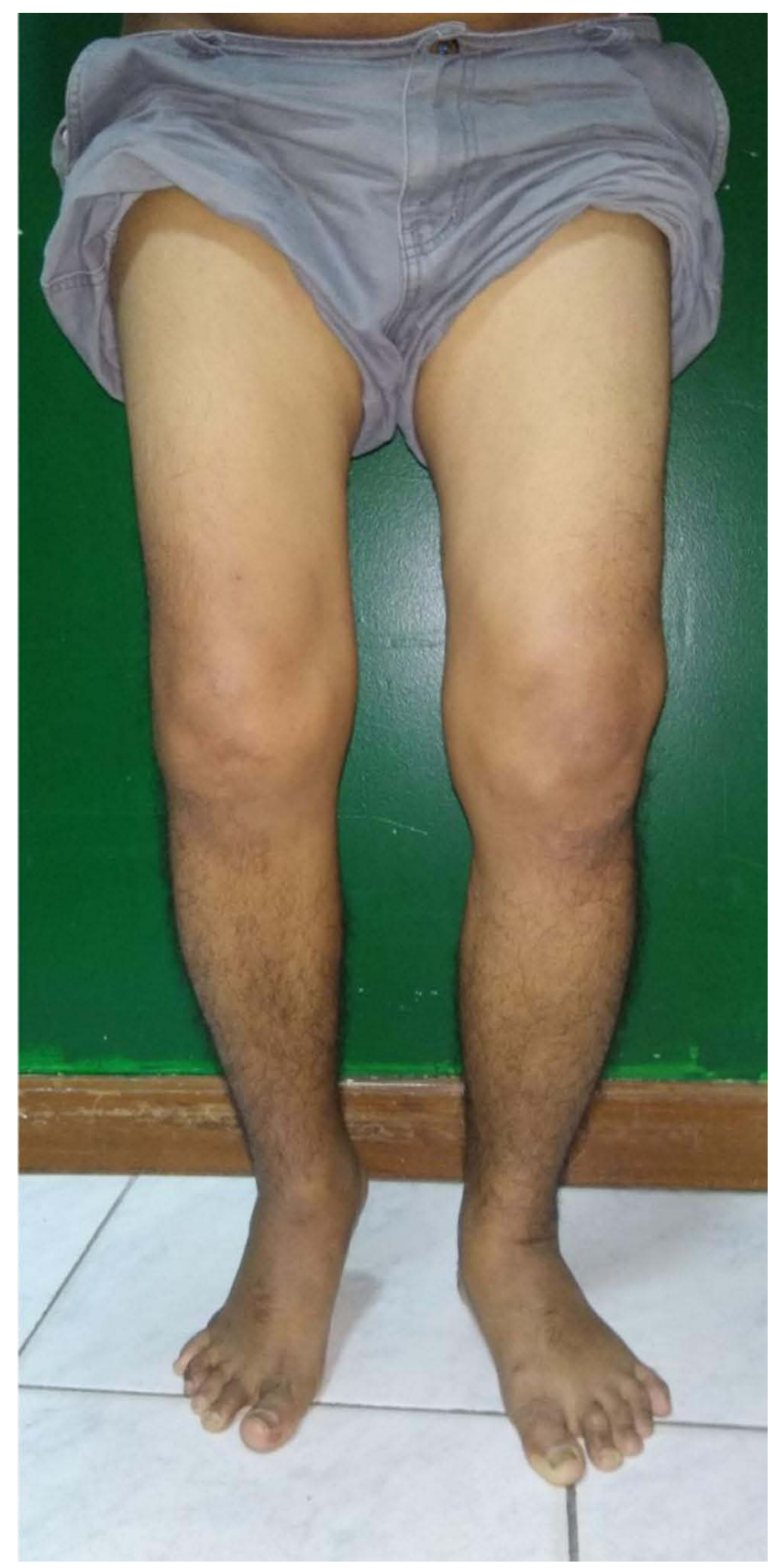

Figure I Clinical pictures of the knee. There was no obvious sign of infection and these pictures show markedly limitations of knee motion. Knee flexion was limited to 80 degree and extension limited to 30 degrees.

about $11.6 \mathrm{mg} / \mathrm{dL}$. Synovial fluid analysis showed an increase in urate crystals as well as polymorphonuclear neutrophils (PMN) count (Table 1).

After explanation and education regarding the problem, informed consent was taken and arthroscopic debridement was obtained and some tissue samples were obtained for pathological analysis. During the surgery, surprisingly, an abundant amount of gouty crystal was found almost on the 


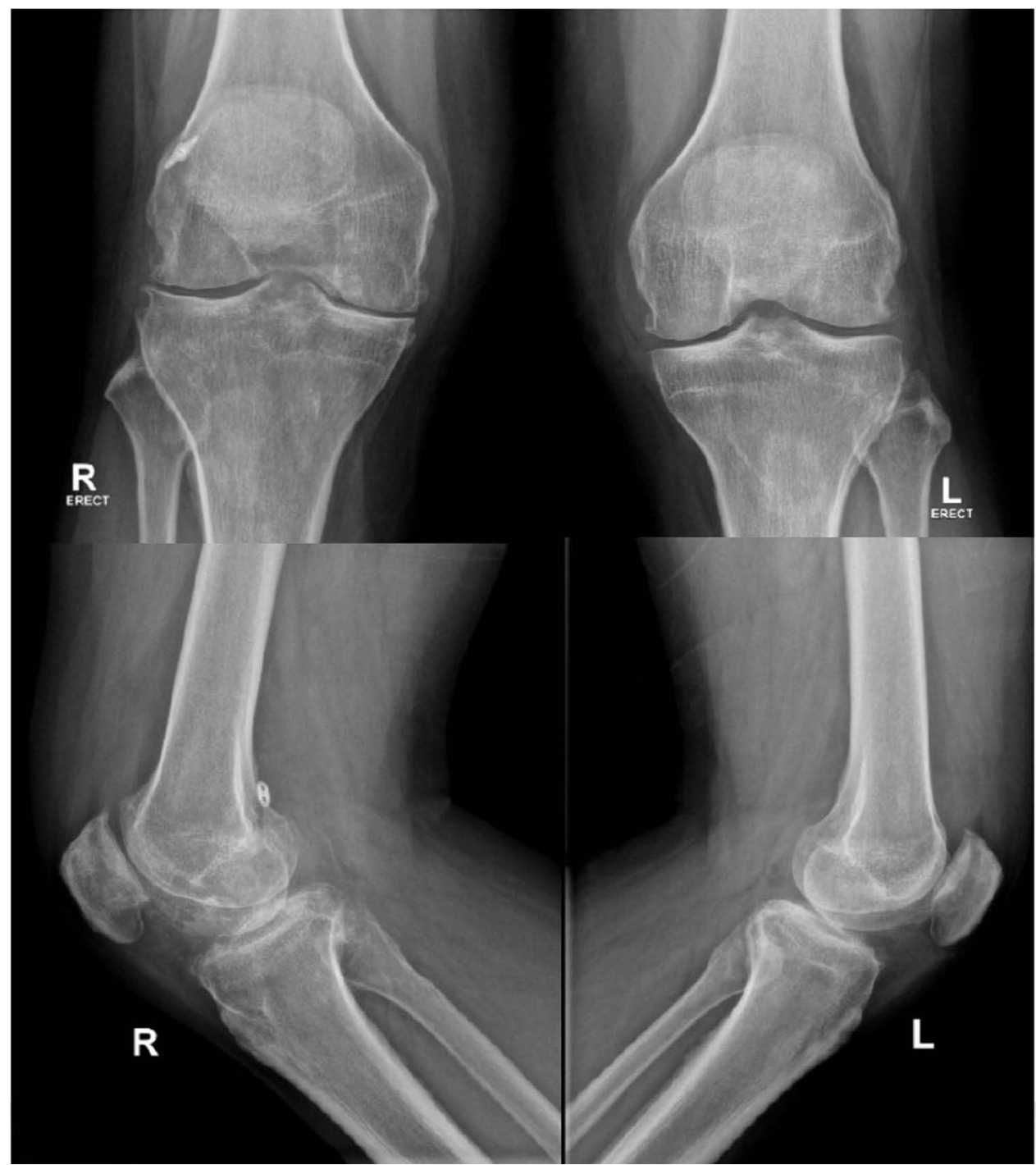

Figure 2 Plan X-ray of the knee shows early arthritic changes on the affected right knee compared to the left knee. On lateral view there is a button that remain on its position on the femoral side.

entire surface of the joint cartilage and synovial tissue (Figure 4). The ACL graft was no longer found and disappeared (Figure 5). A tissue sample was obtained for pathologic anatomy, and revealed pieces of tissue with a needle-shaped structure under a light microscope, respectively. Tophus was seen intraarticularly and numerous urate crystals came out from it. At the time, ACL revision surgery was not obtained with consideration of waiting until optimum condition.

\section{Discussion}

ACL graft failure following a reconstruction still becomes a challenging problem, causing disability. It brings significant issues that contribute to patient's morbidity. Although
ACL reconstruction has been a successful surgery, the number of ACL graft failures is rising over time. ${ }^{3-5}$

Generally, ACL graft failure should be considered when stability restoration and return to activity have not been achieved, other signs found postoperatively are knee joint pain and stiffness. Some factors related to graft failure are technical factors, patient factors, graft selection, and graft tissue. ${ }^{11}$ Other authors define the causes of failure are mechanical due to post-operative trauma, technical error during surgery, and biological factors. ${ }^{3-5}$ Biological graft failure following ACL reconstruction should be considered especially in patient without history of postoperative trauma as well as technical error during surgery. ${ }^{12}$ Biological failure is also determined based on 


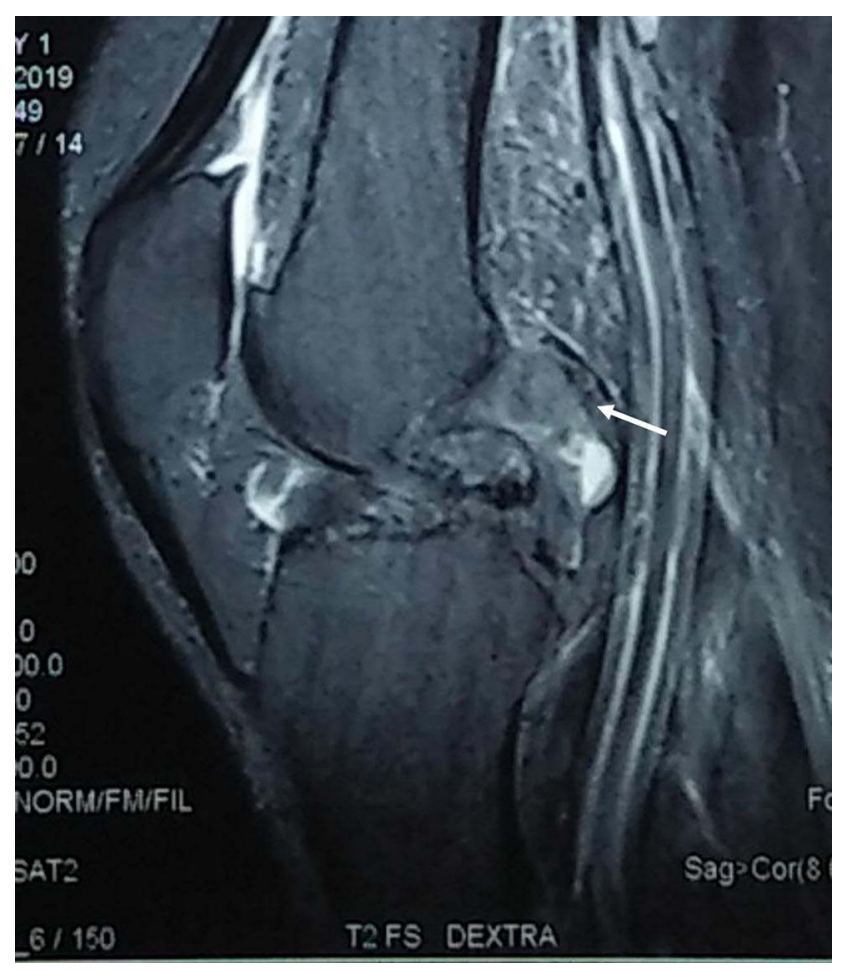

Figure 3 Knee joint MRI of T2 weighted sagittal view show a nodular tissue formation on the posterior part of tibiofemoral joint (white arrow).

microscopic findings and considered if more than a year postoperatively there is laxity of the graft and it shows extensive necrosis, poor vascularity, fragmentation, hypocellularity, and disintegration of collagen. ${ }^{3,13}$ Biological failure is a complex process that still has an unclear mechanism understood. All factors that interfere with graft revascularization, repopulation, and matrix organization can cause graft failure biologically. ${ }^{3}$

In this case report, the exact cause of the failure remains unclear. There was no history of postoperative trauma, and technical errors in the previous surgery could not be ruled out yet in this case. The suspicion of infection as a cause of graft failure cannot be proven.

Table I Pre-Operative Laboratory Result

\begin{tabular}{|l|c|c|}
\hline Category & Result & Reference Values \\
\hline Serum WBC & 7.9 & $(4-10) 1000 / \mu \mathrm{L}$ \\
Serum ESR & 70 & $0-15 \mathrm{~mm}$ \\
Serum CRP & 39.7 & $<5 \mathrm{mg} / \mathrm{L}$ \\
Serum Uric Acid & 11.6 & $3.5-7.2 \mathrm{mg} / \mathrm{dL}$ \\
Synovial fluid clarity & Cloudy & Clear \\
Synovial fluid PMN & $28.80 \%$ & $<25 \%$ \\
Synovial fluid Uric Acid & 12.1 & $<8 \mathrm{mg} / \mathrm{dL}$ \\
\hline
\end{tabular}

Laboratory results before the surgery revealed an increase of Erythrocyte sedimentation rate (ESR) and C-Reactive Protein (CRP), but a normal leukocyte count. Synovial fluid also showed a slight increase in PMN, and no microorganism was found. The presence of contralateral knee similar symptoms and clinical features resemble a knee inflammation raise the possibility of gouty arthritis. Some differential diagnoses, such as chronic inflammation, intraarticular tumor, gout arthritis, synovial chondromatosis, arthrofibrosis, and chronic infection, are thought to be a cause of failure.

Intraoperatively, we found that the intraarticular space was massively filled with crystal urate and tophus formation, and ACL grafts were diminished. Based on that reason, we assumed that severe gouty arthritis results in disorganization of the graft. It started because there is no other possible reason for this condition. A study by Cetin et al. (2014) ${ }^{9}$ showed that tophaceous gout causes internal derangement of the knee joint. In their study revealed some intraarticularly discovered pathology such as subchondral cyst, buckling of posterior cruciate ligament, and ACL discontinuation. Melloni et al. (2004) ${ }^{14}$ revealed that chronic gout infiltrated ACL and medial collateral ligaments. ${ }^{9,14}$

Gout is a common cause of inflammatory joint arthritis. Gout affected $1 \%$ to $2 \%$ of adults and become the most common inflammatory arthritis in men. The prevalence is estimated at 13.6 per 1000 men and 6.4 per 1000 women and increases with increasing age. ${ }^{15}$ Tophaceous gout may present in an atypical and confusing manner. The deposit of it can be affected by various tissues and space in the body such as in tendons, ligaments, bursae, cartilage, bone, subcutaneous, para-articular, and synovial space. Urate crystal deposition was observed on tendons and ligaments or around them. It causes hypertrophy, thickening, degeneration, increased fragility, and loss of elastic character. In an advanced case, rupture of the tendon and ligament are reported. ${ }^{14,16}$ The tendon becomes weak caused by fibrinoid degeneration that lead ischemic change in its structure, resulting in an increasing risk of spontaneous rupture. ${ }^{7}$

\section{Conclusion}

Tophaceous gout presented intraarticularly may be a sign of severe gouty arthritis, which in turn causes severe inflammation leading to internal derangement of the joint. The pathology can affect all tissues around the joint. In this case, it was concluded that severe gouty arthritis of the knee joint is the most suspicious culprit of 


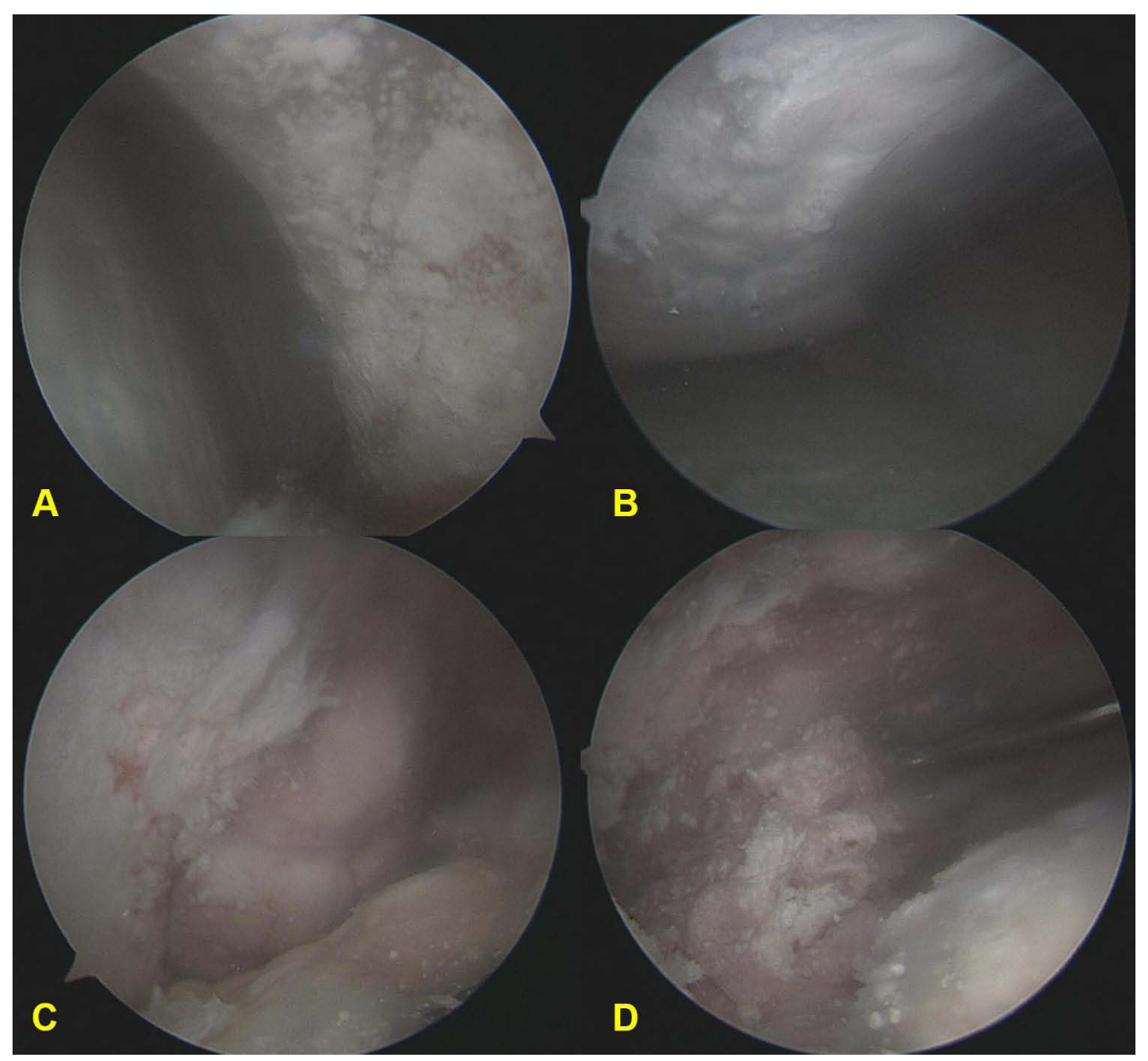

Figure 4 Arthroscopic finding: (A) Abundant crystal urate attached to the entire surface of synovium; (B) Crystal urate envelop the articular surface; (C) Intraarticular tophus formation; (D) Crystal urate comes out from the broken tophus.

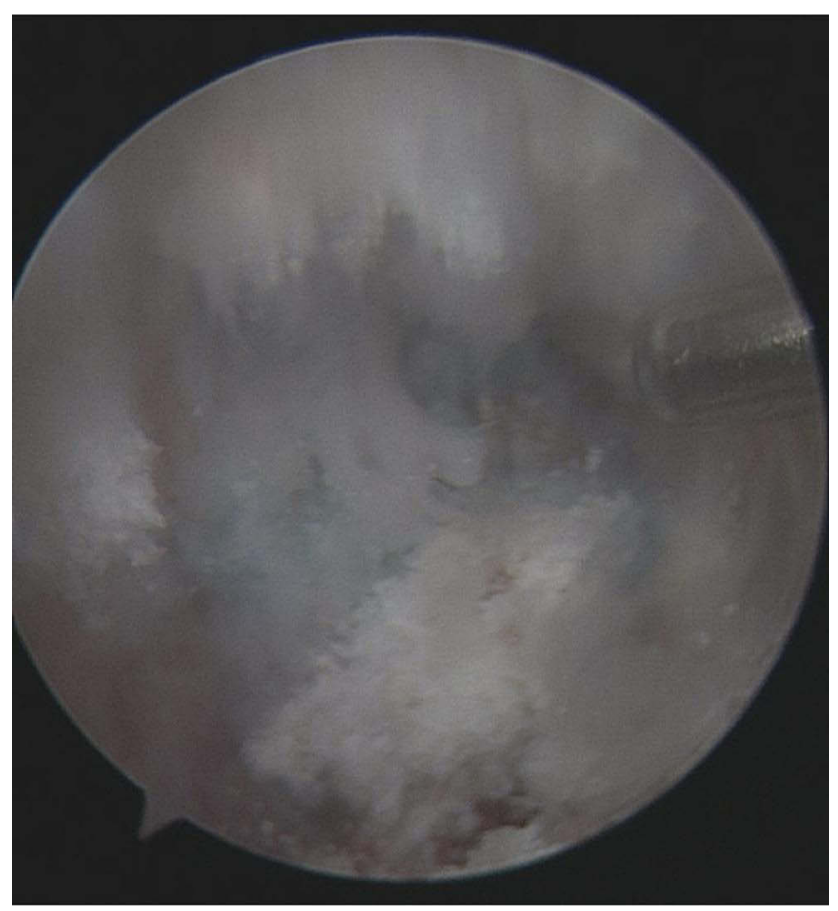

Figure 5 This arthroscopic view shows that loss of $A C L$ graft on its femoral footprint, there was a suture left on the tunnel surface.
ACL graft failure, which resulted in morbidity and loss of stability, although technical errors in previous surgery cannot be ruled out yet.

\section{Abbreviations}

$\mathrm{ACL}$, anterior cruciate ligament; MRI, magnetic resonance imaging; PMN, polymorphonuclear neutrophils; OA, osteoarthritis; ESR, erythrocyte sedimentation rate; CRP, C-reactive protein.

\section{Ethical Approval}

This is a case report; therefore, it did not require ethical approval from ethics committee. However, we have got permission from the patient to publish his data.

\section{Informed Consent}

Written informed consent was obtained from the patient for publication of this case report and accompanying images. A copy of the written consent is available for review by the Editor-in-Chief of this journal on request. 


\section{Disclosure}

The authors report no conflicts of interest in this work.

\section{References}

1. Sanders TL, Maradit Kremers H, Bryan AJ, et al. Incidence of anterior cruciate ligament tears and reconstruction: a 21-year population-based study. Am J Sports Med. 2016;44(6):1502-1507. doi:10.1177/ 0363546516629944

2. Kiapour AM, Murray MM. Basic science of anterior cruciate ligament injury and repair. Bone Jt Res. 2014;3(2):20-31. doi:10.1302/20463758.32.2000241

3. Ménétrey J, Duthon VB, Laumonier T, Fritschy D. "Biological failure" of the anterior cruciate ligament graft. Knee Surg Sports Traumatol Arthrosc. 2008;16(3):224-231. doi:10.1007/s00167-007-0474-x

4. Di Benedetto P, Di Benedetto E, Fiocchi A, Beltrame A, Causero A. Causes of failure of anterior cruciate ligament reconstruction and revision surgical strategies. Knee Surg Relat Res. 2016;28 (4):319-324. doi:10.5792/ksrr.16.007

5. Alentorn-geli E, Cugat R, Farmer KW, Moser MW. Failure of ACL reconstruction. Arch Bone Jt Surg. 2015;3(4):220-240.

6. Ragab G, Elshahaly M, Bardin T. Gout: an old disease in new perspective - a review. J Adv Res. 2017;8(5):495-511. doi:10.1016/j. jare.2017.04.008

7. Hwang HJ, Lee SH, Han SB, et al. Anterior cruciate ligament rupture in gouty arthritis. Knee Surg Sports Traumatol Arthrosc. 2012;20 (8):1540-1542. doi:10.1007/s00167-011-1741-4
8. Sakti M, Usman MA, Lee J, Benjamin M, Maulidiah Q. Atypical musculoskeletal manifestations of gout in hyperuricemia patients. Open Access Rheumatol Res Rev. 2019;11(February):47-52.

9. Cetin P, Tuna B, Secil M, Akar S. Tophaceous gout causing internal derangement of knee joint. J Clin Rheumatol. 2014;20(4):235. doi:10.1097/RHU.0000000000000105

10. Hussin P, Mawardi M, Nizlan NM. The 'Chalky Culprit' of acute locked knee. G Di Chir. 2014;35(9-10):239-240.

11. Sherchan B, Rai S, Tamang N, et al. Outcomes of single bundle arthroscopic anterior cruciate ligament reconstruction in a limited resource setting. J ISAKOS. 2021;6(4):187-192. doi:10.1136/jisakos-2020-000500

12. Akhtar M, Keating J. 25 biological failure following acl reconstruction. $\mathrm{Br} J$ Sports Med. 2015;49(Supp12):A8.3-A9. doi:10.1136/bjsports-2015-095576.25

13. Marumo K, Saito M, Yamagishi T, Fujii K. The "ligamentization" process in human anterior cruciate ligament reconstruction with autogenous patellar and hamstring tendons: a biochemical study. $\mathrm{Am}$ $J$ Sports Med. 2005;33(8):1166-1173. doi:10.1177/036354650 4271973

14. Melloni P, Valls R, Yuguero M, Saez A. An unusual case of tophaceous gout involving the anterior cruciate ligament. Arthroscopy. 2004;20(9):e117-e121. doi:10.1016/S0749-8063(04)00973-9

15. Sumariyono AI. Pedoman Diagnosis Dan Pengelolaan Gout. Penghimpunan Rheumatologi Indonesia; 2018:20.

16. Towiwat P, Chhana A, Dalbeth N. The anatomical pathology of gout: a systematic literature review. BMC Musculoskelet Disord. 2019;20 (1):1-14. doi:10.1186/s12891-019-2519-y

\section{Publish your work in this journal}

The International Medical Case Reports Journal is an international, peer-reviewed open-access journal publishing original case reports from all medical specialties. Previously unpublished medical posters are also accepted relating to any area of clinical or preclinical science. Submissions should not normally exceed 2,000 words or 4 published pages including figures, diagrams and references. The manuscript management system is completely online and includes a very quick and fair peer-review system, which is all easy to use. Visit http://www.dovepress.com/testimonials.php to read real quotes from published authors. 